Orissa Journal of Commerce

Vol. 42, Issue 1, Jan-March 2021

ISSN: 0974-8482

(C) OJC India. All Right Reserved

URL : www.ojcoca.org

DOI: https://doi.org/10.54063/ojc.2021.v42i01.01

\title{
Impact of Idiosyncratic Risk, Systematic Risk and Investor Sentiment on Liquidity of Stock: The Indian Case
}

\author{
Som Sankar Sen ${ }^{1 *}$, Shubha Ranjan Dutta ${ }^{2}$, Abhisek Saha Roy ${ }^{3}$ and Tutun Mukherjee ${ }^{4}$ \\ 1 Associate Professor, Department of Commerce, The University of Burdwan, Burdwan, West Bengal. \\ E-mail:sssen@com.buruniv.ac.in \\ ${ }^{2}$ Assistant Professor of Commerce, Shibpur Dinobundhoo Institution (College), Howrah, West Bengal. \\ E-mail:shubharanjan_dutta02@rediffmail.com \\ ${ }^{3}$ Assistant Professor, Department of Management Studies, Sikekim Manipal Institute of Technology, \\ Sikkim Manipal University, Sikkim.E-mail:asroy.smu@gmail.com \\ ${ }^{4}$ Assistant Professor in Commerce, Xavier Law School, St. Xavier's University, Kolkata, West Bengal. \\ E-mail: tutun.mukherjee@sxuk.edu.in \\ *Corresponding Author
}

To cite this paper

Sen, S.S., Dutta, S.R., Roy, A.S., \& Mukherjee, T. (2021). Impact of

Idiosyncratic Risk, Systematic Risk and Investor Sentiment on

Liquidity of Stock: The Indian

Case. Orissa Journal of Commerce.

42(1), 1-15.

Keywords

Liquidity, Illiquidity, Idiosyncratic risk, Systematic risk, Investor

sentiment, Firm size

JEL Classification

G11, G12, G4, G32

\begin{abstract}
This paper endeavours to investigate the combined impact of volatility, as decomposed into systematic and idiosyncratic risk and investor sentiment on liquidity taking 97 non-financial companies belonging to NIFTY 100 index for the period 2008-09 to 2017-18. Employing panel data technique, it appears that the idiosyncratic risk component of volatility has a significant and positive relationship with illiquidity, while the second component of volatility, viz. systematic risk appears to have no significant relationship with illiquidity. Moreover, the results demonstrate that investor sentiment maintains a significant and negative relationship with illiquidity. However, no significant relationship is found between illiquidity and firm size. The empirical findings have direct implications for stock exchange regulators and corporate managers of Indian non-financial listed firms.
\end{abstract}

\section{Introduction}

Volatility and liquidity are the two characteristics of a stock that receive due importance in financial literature along with the returns of the same. Volatility is the variation of returns for a particular security or market index. The presence of high volatility weakens the performance of the financial market, imposing an adverse impact on economic performance. Increased risk of investment in equity and cost of fund to firms explains volatility in the stock market. Risk and volatility are two terms that are normally used interchangeably. Aït-Sahalia et al. (2012), Amihud and Mendelson (2005), and Chakravarty and Holen (1995) document in their papers that liquidity, as well as volatility, influences risk management, as set pricing, and portfolio construction. 
As argued by Keynes (1930), an asset is more liquid if it can be monetized promptly and without risk. Thus, an asset is liquid if traders can swiftly buy or sell a large volume of it with a negligible price impact. 'Illiquidity' is just the reverse of the liquidity of a stock. Here, assets are not being branded into liquid or illiquid. Rather, it is assumed that on a continuum all assets are illiquid, only the degree of liquidity is varying (Damodaran, 2005). Amihud et al., 1980; Glosten et al., 1985 opined that illiquidity is generated out of selection costs and inventory costs. The cost of illiquidity is nothing but the transaction cost. Thus, less liquid assets bear higher transaction cost (as per cent of asset value) than more liquid assets. Conceptually, illiquidity denotes a situation where the buyer pays a premium, the seller admits discount while executing a market order and when the price is impacted by the order flow. As illiquid stocks are difficult to trade, they are considered a risky asset, contributing to the fact of considering illiquidity as a risk. In continuation of this concept, as there is an established positive association between risk and return, and also a negative (positive) association between return and liquidity (illiquidity), a positive (negative) relationship between illiquidity (liquidity) and risk is also expected. Total risk is decomposed into systematic risk (market risk or non-diversifiable risk) and idiosyncratic risk (unsystematic risk or diversifiable risk).

The present study tries to investigate the impact of idiosyncratic risk, market risk and investor sentiment on the liquidity (measured by Amihud (2002)'s illiquidity) of stock. It may be remembered that any relationship found taking this measure would have a reverse relationship with the liquidity.

\section{Review of Literature}

\subsection{Liquidity and Volatility}

Focusing on the strand of literature that addresses the relationship between liquidity and volatility, empirical studies have found that information opacity ignites volatility and impacts liquidity. For example, Kyle (1985) through his microstructure approach has documented that informational asymmetry amongst investors gives rise to the volatility of price, categorizing these people as noise traders, insiders and market makers. He has argued that the co-existence of this kind of investors having different information sets establishes an affirmative linkage between transaction volume and price change or price impact. Foster et al. (1990), Ho et al. (1981, 1983), Copeland et al. (1983), Stoll (1978a, 1978b) and Amihud et al. (1980) have observed that liquidity and asset volatility are associated negatively. They put forward that information asymmetry and adverse selection costs are two plausible causes of this association. Interestingly, Khine et al. (2011) in a study observed that higher trading activity is linked with lower liquidity and higher levels of volatility for smaller stock portfolios. They claimed that trading activity is a crucial element in defining the link between liquidity and volatility. In comparison to developed countries, Domowitz et al. (2001) observed that developing markets exhibit lower levels of liquidity, as measured by transaction costs and higher levels of volatility. Similar to Amihud et al. (1980), one early study showed that liquidity is reflected by the volatility of the stock, and deep markets are less volatile than the thin ones (Cohen et al., 1976). Securities exchange may be considered as an example of a deep market. It is a form of market in which a huge number of shares can be traded (either purchased or sold) without the price changing dramatically. On the other hand, thin markets are over the counter 
markets. It's worth noting, however, lesser price volatility is the most important aspect of deep markets. Nevertheless, thin markets are much more volatile in both price and volume. Extending the liquidity literature, Chordia et al. (2000) found that price levels, volume, and volatility have significant associations with liquidity. They claimed that besides stock volatility, dispersion in liquidity is driven by price level and volume. Within this framework, Garleanu et al. (2009) argued that large discontinuous changes in prices are difficult to avoid, unlike diffusive changes; because such changes are smooth, continuous and small changes in price. Market makers always take the risk of price changes to their stock so, bidask spreads are fixed to recompense them for holding such inventory risk (Stoll, 1978a; Amihud \& Mendelson, 1980; Ho \& Stoll, 1981; Ho \& Stoll, 1983). As such, jump risk, which is caused by abrupt price swings, is difficult to avoid because dynamic replicating methods are impractical in incomplete markets, suggesting a positive association between jump volatility and illiquidity. In the same line, empirical evidence (Dan Amiram et al., 2016) showed that jump volatility and illiquidity are associated positively; moreover, the study found that diffusive volatility maintains a negative association with illiquidity. In the Korean sample, Lee Jieun and Chung KeeH (2014) observed that an unanticipated increase in market volatility is inversely related to liquidity. They put forward that in stock market, trade proportion plays a pivotal role in establishing association between liquidity and volatility. In a similar vein, Chung and Chuwonganant (2016) found a significant association between market volatility and liquidity in the Korean sample. Acknowledging Lee Jieun and Chung $\mathrm{KeeH}$ (2014), they added stock returns are prospective to change with the different type of traders, like an individual, domestic institutional or foreign institutional. More recently, Kulshrestha et al. (2019) observed that in the case of small and large indexed Indian funds, in an environment of low volatility, liquidity and volatility are not associated with each other. On the contrary, they found an adverse relationship between the former in the case of mid-cap indexed funds. Nevertheless, in an environment of normal volatility for large and mid-cap indexed funds, they have reported a affirmative linkage amid liquidity and volatility. Conversely, a negative link has been found in the case of small-cap indexed funds. In an environment of high volatility, they observed an adverse association amid liquidity and volatility across all the indexed funds. Considering informed stealth trading among a large section of unaware liquidity traders, Admati et al. (1988), and Barclay et al. (1993) documented a significant and positive association between volatility and liquidity, supporting the Stealth trading theory. In the same line, Menyah et al. (1996), Stoll (1978b) and Tinic (1972) have observed an affirmative relationship between volatility and liquidity. For larger equities, like equities traded in the London Stock Exchange, if trading activity increases, volatility also increases. Thus, for large firms' positive relationship may be established between volatility and liquidity. Similar to Tinic et al. (1972), Khine et al. (2011) observed that increased trading activity is constructively connected to higher liquidity and more variable returns, and this result is relevant for the largest firmsize portfolio.

\subsection{Liquidity, Market Risk and Idiosyncratic Risk}

Researchers have very often divided the aggregate volatility of stock into idiosyncratic risk or firmspecific risk and market risk or systematic risk for understanding their impacts on liquidity. Rasin Erik and Stefanovski Marjan (2013) in their study on European equity have found a favourable relationship 
between illiquidity (measured by Amihud illiquidity) and idiosyncratic risk; however, they observed that liquidity (measured by Amivest ratio) and idiosyncratic relationship maintains an adverse relationship. Since European equity can be clustered among developed economies, the result provides a trace that in a developed economy there is an affirmative relationship between idiosyncratic risk and illiquidity. Regarding emerging markets, Kumari et al. (2017) showed that idiosyncratic volatility is more noticeable in India. Moreover, they opined that firm-specific features, viz. ROA, size of the firm, the book-tomarket ratio have a significant association with cross-sectional return variations of firms. They also documented that the firm size, momentum, book-to-market ratio and cash flow to price ratio are potential factors in determining the liquidity-idiosyncratic risk relationship.

In general, it can be said that there should be a positive (negative) association between idiosyncratic risk and illiquidity (liquidity). The reason behind this is, as the liquidity of stock increases, its return tends to decrease, resulting in a decrease in the total risk of a firm. Now as there is an affirmative connection between risk-return, idiosyncratic risk being a part of the total risk of a firm tends to decline along with a decrease in return of a firm because of upward movement of liquidity of the stock. So, a negative (positive) relationship should be there between idiosyncratic risk and stock liquidity (illiquidity). In a developed market (Erik Rasin et al., 2013) and emerging economy (Kumari et al., 2017) such a relationship is observed.

\subsection{Liquidity and Investor Sentiment}

Investor sentiment is another important concern of any stock market. Investment decisions of a particular kind of investors, such as noise traders are not guided by the fundamental information prevailing in any market. Their investment decisions are guided by emotions or psychological feelings towards a particular stock which is also known as investor's sentiment. An investor's sentiment is also known as market sentiment. Researchers have found the surprisingly robust result that investor sentiment and liquidity are significantly associated. For example, more recently, Hu et al. (2019) showed that investor sentiment has a favourable impact on market liquidity. In a similar vein, Liu Shuming (2015) observed that there is a noticeable positive association between investor sentiment and stock market liquidity, suggesting that when sentiment indices rise, the stock market becomes more liquid and trading becomes viable. In emerging economies, Debata et al. (2017) documented that foreign participants' investment sentiment has a strong beneficial impact on liquidity. Extending the research by Debata et al. (2017), Kumari (2019) has observed that institutional investor sentiment also influences liquidity and volatility in the stock market of an emerging economy like India. They claimed that investors' trading behaviour towards a particular stock is influenced by noise impact, overconfidence impact and disposition impact which influence market sentiment, and thereby affect liquidity in the stock market. Within this framework, Baker et al. (2004) put forward that investor sentiment becomes higher as liquidity in the stock market improves through a large number of irrational market makers. As irrational market makers either over-react or under-react to the informational content of the order flows, price impacts go down resulting in higher liquidity in the stock market. In the same line, Shiller (2000) are of opinion that bullish investor sentiment may influence liquidity if irrational market makers are present in the stock market. 
Impact of Idiosyncratic Risk, Systematic Risk and Investor Sentiment on Liquidity of Stock: The Indian Case

Conversely, Huberman and Halka (2001) and DeLong et al. (1990) have argued that investors' trading behaviour and trading patterns guided by noise impact can affect market sentiment which, in turn, can influence liquidity. In this context, Shleifer and Summers (1990) put forward that there can be a deviation of prices from the fundamentals due to noise trading impact that ultimately results in higher volatility and hence a higher cost of trading for the market participants which, in turn, can negatively influence the market liquidity. In support, Statman et al. (2006) added that investors' trading behaviour guided by overconfidence can also influence liquidity through its impact on market sentiment. This view is consistent with the findings of Odean (1998) that observed stock market liquidity increases through a higher level of overconfidence in the market which is marked by higher investor sentiment. Similar to Odean (1998), Shefrin and Statman (1985) documented that investors' trading behaviour is influenced by disposition impact, which in turn shakes market mood and, as a result, stock market liquidity. On the contrary, Sen and Ghosh (2006) found that the above two constructs are associated negatively; however, the study has not found any relationship between liquidity and trading activity.

In general, investor's sentiment and illiquidity (liquidity) should have a negative (positive) relationship. Illiquid stocks possess higher transaction costs for which investors may be less attached to illiquid stocks. So, the higher the illiquidity, the lower is the sentiment attached towards a particular stock by an investor which is also confirmed by the studies mentioned above.

From the above facts and figures, it is mostly observed that studies related to liquidity and volatility have been conducted so far in developed countries. Moreover, such studies have been conducted by either taking time-varying properties or cross-sectional aspect. But no such studies are carried out in the panel framework. The literature study also reveals that there are few studies in the Indian context that investigated the combined impact of idiosyncratic risk and market risk on liquidity or illiquidity. However, it is also perceived that investor sentiment performs a very crucial part in influencing the liquidity of stocks. Thus, the present study seeks to address whether systematic risk, idiosyncratic risk, and investor sentiment have an impact on liquidity in the Indian context.

\section{Objective and Hypotheses of the Study}

\subsection{Objective}

This article endeavours to investigate the combined impact of volatility, as decomposed into systematic and idiosyncratic risk and investor sentiment on liquidity in India.

\subsection{Hypotheses}

Based on the above literature review and objective, the following hypotheses are framed:

$\mathrm{H}_{1}$ : Liquidity (Illiquidity) of stock is negatively (positively) affected by Idiosyncratic risk.

$\mathrm{H}_{2}$ : Liquidity (Illiquidity) of stock is negatively (positively) influenced by market risk

$\mathrm{H}_{3}$ : Liquidity (Illiquidity) of stock is positively (negatively) influenced by investor sentiment.

Orissa Journal of Commerce, 42(1) (C) 2021 
Som Sankar Sen, Shubha Ranjan Dutta, Abbisek Saba Roy and Tutun Mukberjee

\section{Methodology}

\subsection{Data and Sample}

All the required data have been piled up and compiled from the "Capitaline" database. The sample size of the study consists of 97 non-financial companies belonging to the NIFTY 100 index, representing different sectors. The study covers a time-span of ten years, commencing on April 1, 2008, and ending on March 31,2018, and is carried out on uniformly arranged panel data as per financial years, resulting in the exclusion of three companies due to different financial years. The cut-off date for selecting the sample is 31st March 2018.

\subsection{Research Variables}

In this study, three independent variables have been used which are Idiosyncratic Risk, Market Risk and Investor Sentiment. The liquidity of the stock, measured by Amihud (2002) 'illiquidity 'has been considered as the dependent variable. Turnover or sales representing Firm Size (denoted as FS) has been taken as the control variable.

\subsubsection{Market Risk and Idiosyncratic Risk}

Total risk has been decomposed into two parts.

Total risk $=$ Systematic or market risk + Idiosyncratic or firm-specific risk

$$
\sigma_{i}^{2}=\beta_{i}^{2} \sigma_{M}^{2}+\sigma^{2}\left(e_{j}\right)
$$

Systematic Risk (SR) is taken as the product of squared beta $\left(\beta_{i}^{2}\right)$ and Variance of market return $\left(\sigma_{M}^{2}\right)$, where beta $(\beta)$ is the slope of the Security Market Line (SML). In the present study weekly stock returns have been regressed on the weekly market return (the market is represented by the NIFTY 100 index).

On the other hand, to calculate Idiosyncratic Risk (IR), simple regression has been run taking stock return as the target variable and market return as the predictor variable over 52 weeks or 1 year for each company's stock. The residuals of the regression have been squared to get the variances $\left[\sigma^{2}\left(e_{i}\right)\right]$ which are the Idiosyncratic Risk for each stock for each year.

\subsubsection{Investor Sentiment (IS)}

Investor Sentiment has been calculated in the following manner:

The volume of stock for a particular year $=\Sigma_{1}^{n} V o l_{i, t}$

Where $\mathrm{Vol}=$ Volume of stock, $i=i^{\text {th }}$ stock and $\mathrm{t}=1,2 \ldots \ldots \ldots . \ldots 2$ (As 1 year is equivalent to 52 weeks).

Investor's sentiment $=\ln \left(\mathrm{Vol}_{\mathrm{t}}\right)-\ln \left(\mathrm{Vol}_{\mathrm{t}-1}\right)$.

According to Baker et al. (2004), the trading volume trend, which is defined as an increase in trading volume per unit of time, can be used to measure investor sentiment on specific equities. The 
Impact of Idiosyncratic Risk, Systematic Risk and Investor Sentiment on Liquidity of Stock: The Indian Case

trading volume trend is a preferable sentiment metric as compared to the level of the trading volume; because it arrests the traces of overconfident investors on the market and mitigates the issue of mixing investor sentiment information with liquidity information.

\subsubsection{Liquidity (Illiquidity)}

In this study, Amihud (2002)'s measure of 'illiquidity' has been used as the proxy of liquidity of the stock (denoted as ILL). Amihud's illiquidity is the reciprocal of stock liquidity and is defined here as the average ratio of the weekly absolute return to the volume on that week, $\left|R_{i j w}\right| / V O L W_{j y w} \cdot R_{i j w}$. is the return of stock $i$ on week $w$ of year $t$ and $V O L W$ is the weekly volume. The above ratio gives the absolute (percentage) price change per rupee of weekly trading volume or the weekly price impact of the order flow.

Thus Illiquidity $\left(\operatorname{ILLIQ_{ij}}\right)=1 / W_{i j} \sum_{t=1}^{W i y}\left|R_{i j w}\right| / V O L W_{i j w}$

Where $W_{i, y}$ is the number of weeks for which data are available for stock $i$ in year $y$. To get a meaningful result of Illiquidity the above figure is multiplied by $10^{7}$.

\subsection{Methods}

\subsubsection{Unit Root Test}

To look over the stationarity of panel data and the order of integration, it is necessary to carry out the unit root test.

For this purpose Im, Pesaran and Shin (IPS, hereafter) test has been chosen. IPS initiates by postulating a distinct ADF regression for each cross-section with individual effects and no time trend:

$$
\Delta y_{i t}=\alpha_{i}+\rho_{i} y_{i, t-1}+\sum_{j=1}^{p_{i}} \beta_{i j} \Delta y_{i, t-j}+\varepsilon_{i t}
$$

where $i=1, \ldots, N$ and $t=1, \ldots, T$

After estimating the separate ADF regressions, the average of the $t$-statistics for $p_{i}$ from the individual ADF regressions, $t_{i T i}\left(\phi_{i}\right)$ is calculated:

$$
\bar{i}_{N T}=\frac{1}{N} \sum_{i=1}^{N} t_{i T}\left(p_{i} \beta_{i}\right)
$$

Next, the $t$-bar is standardized that converges to the standard normal distribution as $N$ and $T$ $\rightarrow \infty$. If the $W$-t-bar statistic is significant there is no unit root.

\subsubsection{Panel Regression}

For the first-hand investigation, three options are available. a) Pooled OLS model, b) The Fixed Effects Model (FEM) and c) The Random Effects Model (REM). 
a) In the Pooled OLS model, 970 observations $(97 * 10)$ can be pooled for estimating a pooled regression:

$$
I I L_{i t}=\beta_{1}+\beta_{2} I R_{i t}+\beta_{3} S R_{i t}+\beta_{4} I S_{i t}+\beta_{5} F S_{i t}+\mu_{i t}
$$

Where $\mathrm{i}$ (company) $=1,2 \ldots 97$ and $\mathrm{t}$ (time) $=1,2,3,4, . ., 10$. In this model, the regressors are assumed to be non-stochastic. Moreover, if the regressors are found to be stochastic, they are uncorrelated with the error term $\left(\mu_{i}\right)$.

b) In the Fixed Effects Model, similar to the Pooled OLS Model, 970 observations will be pooled, but each cross-section unit (in this case, companies) will have its own dummy variable (intercept term). The model can be carved in the following equation:

$$
I L L_{i t}=\beta_{1 i}+\beta_{2} I R_{i t}+\beta_{3} S R_{i t}+\beta_{4} I S_{i t}+\beta_{5} F S_{i t}+\mu_{i t}
$$

The absence of subscript ' $t$ ' in the intercept term $\beta_{1 i}$ suggests that the intercepts of each of the 97 company's do not differ over time.

c) In the REM, it is assumed that the intercept values are drawn randomly from a larger population of companies. In the present case, the sample of 97 companies have been drawn from a universe of similar companies, and the intercept $\left(\beta_{1}\right)$ has a shared mean value. The individual differences in each company's intercept value is reflected in the error term $\left(\varepsilon_{i}\right)$. Hence, the model can be represented as:

$$
\begin{aligned}
I L L_{i t} & =\beta_{1}+\beta_{2} I R_{i t}+\beta_{3} S R_{i t}+\beta_{4} I S_{i t}+\beta_{5} F S_{i t}+\mu_{i t}+\varepsilon_{i} \\
& =\beta_{1}+\beta_{2} I R_{i t}+\beta_{3} S R_{i t}+\beta_{4} I S_{i t}+\beta_{5} F S_{i t}+w_{i t}
\end{aligned}
$$

Where, $w_{i t}=\mu_{i t}+\varepsilon_{i}$. Here $\varepsilon_{i}$ is the individual specific or cross-sectional specific error component and $\mu_{i t}$ is the combined time series and cross-sectional error component.

The Breusch Pagan Test is used to see if there are any random effects.

$$
H_{0}: \sigma_{\mu}^{2}=0
$$

The test statistic is $L M=\frac{N T}{2(T-1)}\left(\frac{\sum_{i=1}^{N}\left(\sum_{t=1}^{T} e_{i t}\right)^{2}}{\sum_{i=1}^{N} \Sigma_{t=1}^{T} e^{2} i t}-1\right)$

LM statistics has a Chi-square distribution with one difference. As a result, if the calculated value of LM is significant, $H_{0}$ will now be rejected and random effects will ensue.

The Hausman Test is used to distinguish between fixed and random effects.

The Hausman statistics have a $\chi^{2}$ distribution and is calculated as follows:

Where;

$$
H=(b-B)^{\prime}\left(V_{-} b-V_{-} B\right)^{-1}(b-B)
$$

$\mathrm{B}=$ is the coefficient vector from the consistent estimator. 
Impact of Idiosyncratic Risk, Systematic Risk and Investor Sentiment on Liquidity of Stock: The Indian Case

$\mathrm{B}=$ is the coefficient vector from the efficient estimator.

$\mathrm{V} \_\mathrm{b}=$ is the covariance matrix of the consistent estimator.

V_B = is the covariance matrix of the efficient estimator.

$H_{0}$ : Difference in the coefficient not systematic.

If the $\mathrm{H}$ statistics is significant the $H_{0}$ is rejected and the fixed effect model is taken and vice versa.

\section{Data and Analysis}

\subsection{Descriptive Statistics}

Table 1 reports the descriptive statistics of variables used in this study. The number of firm-year observations is 970 for each variable. The mean value of IR is 0.0486 with a maximum of 0.1385 and a minimum of 0.0058 . The SR ranges from a minimum of $2.95 \mathrm{e}-14$ to a maximum of 0.0012 , with a mean of 0.0001 . The IS varies from -2.3374 to 2.8726 with a mean value of 0.1274 . The mean value of ILL is 6.5639 with a maximum of 1573.2110 and a minimum of 3.95E-09. In terms of the control variable, the mean FS is 22595.7200 with a maximum of 516681.1600 and a minimum of 158.5700 .

Table 1: Descriptive Statistics

\begin{tabular}{lccccc}
\hline & ILL & IR & SR & IS & FS \\
\hline Mean & 6.5639 & 0.0486 & 0.0001 & 0.1274 & 22595.7200 \\
Standard Error & 2.0102 & 0.0005 & 0.0000 & 0.0215 & 1941.2559 \\
Median & 0.1283 & 0.0448 & 0.0000 & 0.0737 & 4102.800 \\
Standard Deviation & 62.5982 & 0.0180 & 0.0001 & 0.6703 & 60450.7100 \\
Sample Variance & 3918.5410 & 0.0003 & $1.00 \mathrm{e}-08$ & 0.4493 & $3.65 \mathrm{e}+09$ \\
Kurtosis & 446.1471 & 5.0577 & 35.7927 & 5.1690 & 31.7769 \\
Skewness & 19.5970 & 1.1720 & 4.6184 & 0.5795 & 5.0606 \\
Minimum & $3.95 \mathrm{e}-09$ & 0.0058 & $2.95 \mathrm{e}-14$ & -2.3374 & 158.5700 \\
Maximum & 1573.2110 & 0.1385 & 0.0012 & 2.8726 & 516681.6000 \\
Count & 970 & 970 & 970 & 970 & 970 \\
\hline
\end{tabular}

Source: Authors' tabulation

\subsection{Correlation Analysis}

To see the degree of association the correlations between the variables have been calculated and results are reported in Table 2. The results show that there is a positive correlation between illiquidity and both IR and SR. Conversely, a negative association is there between illiquidity and IS. However, there is no degree of association between illiquidity and FS.

Orissa Journal of Commerce, 42(1) (C) 2021 
Som Sankar Sen, Shubha Ranjan Dutta, Abbisek Saba Roy and Tutun Mukberjee

Table 2: Correlation Matrix

\begin{tabular}{lccccc}
\hline Variables & ILL & IR & SR & IS & FS \\
\hline ILL & 1 & & & & \\
IR & $0.1687^{*}$ & 1 & & & \\
SR & $0.1041^{*}$ & $0.4220^{*}$ & 1 & & \\
IS & $-0.0901^{*}$ & $0.2105^{*}$ & 0.0370 & 1 & 1 \\
FS & -0.0373 & -0.0277 & -0.0277 & 0.0057 & \\
\hline
\end{tabular}

Source: Authors' tabulation

Notes: * Significant at $1 \%$ level, ** Significant at 5\% level.

\subsection{Unit Root Test}

Table 3 presents the results of the unit root test for the variables used in this study. The W-t bar statistics for all the variables are significant at the $1 \%$ significant level. Hence, all variables are stationary at level or $\mathrm{I}(0)$.

Table 3: Unit Root Test Results

\begin{tabular}{ccc}
\hline Variables & W-t-barstatistic & $p$-value \\
\hline ILL & $-96.1503^{*}$ & 0.0000 \\
IR & $-12.4577^{*}$ & 0.0000 \\
SR & $-1.3 e+02^{*}$ & 0.0000 \\
IS & $-11.7855^{*}$ & 0.0000 \\
FS & $-2.2463^{*}$ & 0.0123 \\
\hline
\end{tabular}

Source: Authors' tabulation

Notes: * Significant at 1\% level

\subsection{Regression Results}

Estimated results of three regression models (equations 3, 4 and 5 respectively) have been presented in Table 4. A close look at the figures reported in Table 4 reveals that there are consistent results for the significance of the coefficients are concerned. One can observe that ILL is positively influenced by IR and conversely, IS has a negative impact on ILL. All three models are agreed that SR and FS do not influence ILL. Hence, the results are robust.

To choose the best model among these three two steps have been followed. Breusch Pagan Test shows that (Table 5) LM Statistic (13.22) is highly significant. Therefore, Pooled OLS Model is rejected. Finally, the Hausman Test shows that (Table 6) H statistic (4.29) is not significant. Hence, the null hypothesis cannot be rejected and the Random Effects Model would be the better model among the Random Effects Model and the Fixed Effects Model. 
Impact of Idiosyncratic Risk, Systematic Risk and Investor Sentiment on Liquidity of Stock: The Indian Case

Table 4: Regression Results

\begin{tabular}{lccc}
\hline \multicolumn{3}{c}{ Models } \\
\hline Variables & Pooled OLS & FEM & REM \\
\hline IR & $625.6187^{*}$ & $687.8603^{*}$ & $635.8539^{*}$ \\
& $(5.06)$ & $(4.53)$ & $(4.92)$ \\
SR & 20191.33 & 25658.63 & 20694.1 \\
& $(0.93)$ & $(1.14)$ & $(0.96)$ \\
IS & $-12.06179^{*}$ & $-13.7194^{*}$ & $-12.59505^{*}$ \\
& $(-4.01)$ & $(-4.56)$ & $(-4.27)$ \\
FS & -.0000184 & .0001747 & -.000012 \\
& $(-0.56)$ & $(1.21)$ & $(-0.32)$ \\
Constant & $-23.01664^{*}$ & $-30.49202^{*}$ & $23.6014^{*}$ \\
& $(-3.83)$ & $(-3.61)$ & $(-3.65)$ \\
$R^{2}:$ within & - & 0.0455 & 0.0436 \\
$\quad$ : between & - & 0.0062 & 0.0629 \\
: overall & 0.0461 & 0.0256 & 0.0461 \\
Adj. $R^{2}$ & 0.0421 & - & - \\
F & $11.66^{*}$ & $10.35^{*}$ & - \\
Wald chi2(4) & - & - & $45.66^{*}$ \\
$\mathrm{~N}$ (group) & $970(97)$ & $970(97)$ & $970(97)$ \\
\hline
\end{tabular}

Source: Authors' tabulation

Notes: * Significant at 1\% level. Figures in the parenthesis denote t-value (FEM) or z-value (REM).

Table 5: Breusch and Pagan Lagrangian Multiplier Test for Random Effects

\begin{tabular}{lcc}
\hline & Var & $s d=\operatorname{sqrt}($ Var $)$ \\
\hline ILL & 3918.541 & 62.59825 \\
$\mathrm{e}$ & 3536.562 & 59.469 \\
$\mathrm{u}$ & 217.3618 & 14.74319 \\
\hline
\end{tabular}

Test: $\operatorname{Var}(\mathrm{u})=0$

$\operatorname{chibar} 2(01)=13.22^{*}$

Source: Authors' tabulation

Notes: * Significant at 1\% level.

Table 6: Hausman Test Results

\begin{tabular}{lcccc}
\hline & $(b)$ & $(B)$ & $(b-B)$ & sqrt $\left(\operatorname{diag}\left(V_{-} b-V_{-} B\right)\right)$ \\
\hline & $\mathrm{Fe}$ & $\mathrm{Re}$ & Difference & S.E. \\
$\mathrm{IR}$ & 687.8603 & 635.8539 & 52.0063 & 79.6835 \\
SR & 25658.63 & 20694.1700 & 4964.4670 & 6351.2260 \\
IS & -13.7194 & -12.5950 & -1.1243 & 0.5865 \\
T & 0.0001 & -0.0000 & 0.0001 & 0.0001 \\
& \multicolumn{2}{c}{ chi2 $(3)=4.29$} \\
\end{tabular}

Source: Authors' tabulation

Orissa Journal of Commerce, 42(1) (C) 2021 
Som Sankar Sen, Shubha Ranjan Dutta, Abbisek Saba Roy and Tutun Mukherjee

\section{Results and Discussion}

The acceptance of REM proposes that the difference in coefficients is systematic to explain that $\mu_{i}$ is uncorrelated. The results shown in Table 4 indicate that there is a significant positive relationship between Idiosyncratic Risk (IR) and Illiquidity (ILL). The finding is supported by the coefficient (635.8539) and the p-value (0.000). The result strongly accepts $\mathrm{H}_{1}$. Since the present study finds a positive association between idiosyncratic or firm-specific risk and the illiquidity of stock, it can be concluded that the illiquidity of stock tends to increase along with the upward movement of firmspecific risk. This result is in line with the findings of Sen and Ghosh (2008b). Sen and Ghosh (2008b) have reported some significant relationships between accounting variables and liquidity. Therefore, a reduction in the firm-specific risk will boost the liquidity of the stock. The above table also highlights that the coefficient of Systematic Risk (SR) is positive (i.e., 20694.17) supported by a p-value of 0.336 indicating no statistically significant relationship between Systematic Risk (SR) and Illiquidity (ILL) of stock. Sen and Ghosh (2008a) find a joint positive effect of macroeconomic variables on aggregate market liquidity. However, no relationship is found in the present study between the Systematic Risk (SR) and Illiquidity (ILL) of stock. Thus, the result cannot reject the null of $\mathrm{H}_{2}$. From the above table, it is also apparent that the coefficient of Investor Sentiment is negative(i.e.-12.59505) supported by a $\mathrm{p}$-value of 0.000 indicating a statistically significant negative relationship between Investor Sentiment(IS) and Illiquidity(ILL) of stock indicating that the illiquidity of the stock decreases due to a favourable Investor Sentiment towards a stock. Hence, positive Investor Sentiment is a real liquidity booster. Thus, the result strongly accepts $\mathrm{H}_{3}$. Furthermore, no relationship is found between the control variable and the dependant variable signifying that firm size is not a key factor in this study as the sample consists of the largest 97 firms in the market.

\section{Conclusion}

The present study is focused on how the firm-specific risk, i.e., idiosyncratic risk and market risk together influence the illiquidity of stock in the Indian share market and also the psychology of investors towards a particular stock, i.e., investor sentiment affects the illiquidity of stock in the Indian stock market.

This study hypothesized that higher illiquidity is associated with higher risk indicating a positive association among idiosyncratic risk, market risk and illiquidity because of the direct relationship between risk and return. On the other hand, theoretically, there should be a negative (positive) relationship between illiquidity (liquidity) of stock and Investor Sentiment because higher transaction cost is involved in case of illiquidity of stock and due to much higher cost of trading, investors show the lesser amount of willingness towards that particular stock indicating a negative association between illiquidity and investor sentiment.

The results of this study indicate that illiquidity has a positive and negative association with idiosyncratic risk and investor sentiment respectively, finally accepting $\mathrm{H}_{1}$ and $\mathrm{H}_{3}$. However, the study does not find any significant relationship between Illiquidity and market risk.

This study has some theoretical and practical implications. First, since the firm-specific risk is diversifiable, so measures may be taken to reduce this kind of risk to boost liquidity. Second, investor sentiment has shown to be playing a pivotal role in decreasing illiquidity and thus improving liquidity; 
Impact of Idiosyncratic Risk, Systematic Risk and Investor Sentiment on Liquidity of Stock: The Indian Case

the importance of 'Analysts Coverage' and reputation building cannot be ignored. Further study in this respect may open new areas in research. Finally, the present study does not find any association between liquidity and firm size. A study might be very interesting taking a sample from midcap shares in this regard.

\section{References}

Admati, A.R. and Pfleiderer, P. (1988). A Theory of intraday patterns: Volume and price variability. The Review of Financial Studies, 1(1), 3-40.

Albert S. Kyle. (1985). Continuous Auctions and Insider Trading. Econometrica, 53(6), 1315-1336.

Amihud, Y., and Mendelson, H. (1980). Dealership market: market making with inventory.Journal of Financial Economics, 8, 31-53.

Amihud, Y. (2002). Illiquidity and stock returns: cross-section and time-series effects. Journal of Financial Markets, 5, 31-56.

Amihud, Y., Mendelson. H.; and Pedersen, L.H. (2005). Liquidity and Asset Prices. Foundations and Trends in Finance, 1(4), 269-364.

Ait-Sahalia, Y., Jacod, J., and Li, J. ( 2012). Testing for jumps in noisy high frequency data, Journal of Economics, 168(2), 207-222. doi:10.1016/j.jeconom.2011.12.00.

Barclay, M.J., and Warner, J.B. (1993).Stealth trading and volatility: which trades move prices? Journal of Financial Economics, 34(3), 281-305.

Baker, M. and Stein, J.C. (2004). Investor Sentiment and the Cross-Section of Stock Returns, NBER Working Paper\#10449.

Baker, M., \& Stein, J.C. (2004). Market liquidity as a sentiment indicator. Journal of Financial Markets, 7(3), 271299.

Brown, G.W. and Cliff, M.T. (2005).Investor Sentiment and Asset Valuation. Journal of Business, 78(2), 405-440.

Chakravarty, S. and Holden, C.W. (1995). An Integrated Model of Market and Limit Orders. Journal Financial Intermediation. 4(3), 213-241. doi:10.1006/jfin.1995.1010.

Chordia, T., Roll, R., and Subrahmanyam, A. (2000). Commonality in liquidity, Journal of Financial Economics. 56(1), 3-28.

Chung, K. H. and Chuwonganant, C. (2016). Market Uncertainty, Liquidity, and Stock returns. University at Buffalo Working Paper, The State University of New york.

Cohen, K. J., Ness, W. L., Okuda, H., Schwartz, R. A., and Whitcomb, D. K. (1976). The Determinants of Common Stock Returns Volatility: An International Comparison. The Journal of Finance, 31(2), 733-740.

Copeland, T, E. and Galai, D. (1983). Information Effects on the Bid-ask Spread. The Journal of Finance, 38(5), 1457-1469.

Dan, A., Balazs, C., and Ariel, L. (2016). Volatility, Liquidity and Liquidity Risk. Retrived from : file://F:/ LIQUIDITY\%20AND\%20VOLATILITY\%20PAPERS/ACLBurton.pdf

Damodaran, A. (2005). Marketability and value: Measuring the illiquidity discount. SSRN Electronic Journal. https:/ /doi.org/10.2139/ssrn.841484

Debata, B., Dash, S. R., and Mahakud, J. (2017). Investor Sentiment and emerging stock market liquidity. Finance Research Letters, 26, 15-31. 
De Long, J.B., Shleifer, A., Summers, L.H., and Waldmann, R.J. (1990). Noise trader risk in financial markets. Journal of Political Economy, 98(4), 703-738.

Domowitz, I., Glen, J., and Madhavan, A. (2001). Liquidity, Volatility and Equity Trading Costs Across Countries and over time. International Finance, 4, 221-255.doi:10.1111/1468-2362.00072.

Foster, F. D., and Viswanathan, S. (1990). A Theory of the Interday Variations in Volume, variance, and Trading Costs in Securities markets. The Review of Financial Studies,3(4),593-624.

Garleanu, N. (2009). Portfolio choice and pricing in illiquid markets. Journal of Economic Theory, 144(2), 532-564.

Glosten, L. and Milgrom, P. (1985). Bid, ask, and transaction prices in a specialist market with heterogeneously informed trader. Journal of Financial Economics, 14(1), 71-100.

Ho, T. and Stoll, H.R. (1981). Optimal Dealer Pricing under Transactions and return Uncertainty, Journal of Financial Economics, 9(1), 47-73.

Ho, T. and Stoll, H.R. (1983). The Dynamics of Dealer Markets under Competition. The Journal of Finance, 38(4), 1053-1074.

Huberman, G. and Halka, D. (2001). Systematic liquidity. Journal of Financial Research, 24(2), 161-178.

Keynes, and John Maynard. (1930). A treatise on money. Macmillan.

Khine, K. and Hiller, D. (2011). A reexamination of the relationship between volatility, liquidity and trading activity. Pecvnia: Revista de la Facultad de Ciencias Económicas y Empresariales, Universidad de León. 3345. DOI: http://dx.doi.org/10.18002/pec.v0i2011.751

Kulshrestha, K. and Bhaduri, S. N. (2019). The Joint Dynamics of Liquidity and Volatility Across Small and Large index Indian Funds. Journal of Emerging Market Finance,1-16, Retrieved from DOI:10.1177/09726527/ 9846318

Kumari, J., Mahakud, J., and Hiremath, G. S. (2017). Determinants of idiosyncratic volatility: Evidence from the Indian stock market. Research in International Business and Finance. 41, 172-184.

Kumari, J. (2019). Investor Sentiment and stock market liquidity: Evidence from an emerging economy. Journal of Behavioral and Experimental Finance, 23,166-180.

Lee, J. and Chung, K. H. (2014). The Effect of Market Volatility on liquidity and Stock returns in the Korean Stock Market. Working Paper,1-37, Retrieved from file:///F:/LIQUIDITY\%20AND\% 20VOLATILITY\%20PAPERS/wp-2017-18.pdf

Liu, S. (2015). Investor Sentiment and Stock Market Liquidity. Journal of Behavioural Finance, 16(1), 51-67.

Menyah, K. and Pandyal, K. (1996). The determinants and dynamics of bid-ask spreads on the London Stock Exchange. Journal of Financial Research, XIX (3), 377-394.

Odean, T. (1998).Volume, volatility, price and profit when all traders are above average.Journal of Finance, 53,75-109.

Rasin, E. and Stefanovski, M. (2013). Effects of Liquidity on Idiosyncratic Risk. Retrieved from https:// pdfs.semanticscholar.org/9933/856154e133929119fd73443e53fa48ab2797.pdf

Sen, S. S., and Ghosh, S.K. (2006). Relationship between Stock Market Liquidity and Volatility at an Aggregate Level: A Case Study on NSE. The ICFAI Journal of Applied Finance, 3(4), 39-46.

Sen, S. S., and Ghosh, S.K. (2008a). Association between Stock Market Liquidity and Some Selected Macroeconomic Variables: A Case Study on Indian Stock Market. The Icfai University Journal of Financial Economics, VI (3), 5373.

Sen, S. S., and Ghosh, S.K. (2008b). The Association between Market Liquidity at the Scrip Level and Accounting Variables: The Indian Evidence. Indian Journal of Finance, II(8), 20-31. 
Impact of Idiosyncratic Risk, Systematic Risk and Investor Sentiment on Liquidity of Stock: The Indian Case

Shefrin, H., and Statman, M. (1985). The disposition to sell winners too early and ride losers too long: theory and evidence. The Journal of Finance, 40(3), 777-790.

Shiller, R.J. (2000).Irrational Exuberance. Princeton University Press, Princeton NJ.

Shleifer, A. and Summers, L. H. (1990). The noise trader approach to finance. The Journal of Economic Perspectives, 4(2), 19-33.

Shulan, H., Meiling, Z., and Cai, Y. (2019). Impact of Investor Behavior and Stock Market Liquidity: Evidence from China. 21(11), 1111. Retrieved from entropy-21-01111.pdf

Smid,. S. (1968). A new look at the random walk hypothesis. Journal of Financial \& Quantitative Analysis, 3(3), 235261.

Statman, M., Thorley, S., and Vorkink, K. (2006). Investor overconfidence and trading volume. Review of Financial Studies, 19(4), 1531-1565.

Stoll, H.R. (1978a). The supply of Dealer Services in securities markets. The Journal of Finance, 33(4), 1133-1151.

Stoll, H.R. (1978b). The Pricing of Security Dealer Services in securities markets. The Journal of Finance, 33(4), 1153-1172.

Tinic, S.M. (1972). The economics of liquidity services. Quarterly Journal of Economics, 79-93. 